\title{
Cost saving of switching to equivalent inhalers and its effect on health outcomes
}

Corresponding author:

Cl Bloom, chloe.bloom06@imperial.ac.uk, Department of Respiratory Epidemiology, Occupational Medicine and Public Health, National Heart Lung Institute, Imperial College London, Emmanuel Kaye Building, 1b Manresa Road, London, SW3 6LR. Telephone +44 (0)20 75948821.

All other authors:

I Douglas, ian.douglas@Ishtm.ac.uk, London School of Hygiene and Tropical Medicine, Epidemiology and Population Health, LSHTM Keppel Street, London, WC1E 7HT, UK.

J Olney, jack.olney@imperial.ac.uk, Centre for Health Economics \& Policy Innovation, Imperial College London, UK.

G d'Ancona, grainne.dancona@gstt.nhs.uk, Guy's \& St Thomas's NHS Trust, London, UK.

L Smeeth, liam.smeeth@Ishtm.ac.uk, London School of Hygiene and Tropical Medicine, Epidemiology and Population Health, LSHTM Keppel Street, London, WC1E 7HT, UK.

JK Quint, j.quint@imperial.ac.uk, Department of Respiratory Epidemiology, Occupational Medicine and Public Health, NHLI, Imperial College London, London, UK.

Key words: inhaler devices, asthma, COPD epidemiology

Word count: 3767 


\section{What is the key question?}

Physicians and patients alike are often reticent to switch to an equivalent inhaler to reduce NHS costs, but it is a commonly encouraged local policy in the UK due to increasing NHS financial pressures; what is the impact of such a policy on patients' health (exacerbations and symptoms) and healthcare utilisation (GP consultations)?

\section{What is the bottom line?}

The findings from this real-world study support the cost-saving clinical practice of switching to cheaper equivalent inhalers.

\section{Why read on?}

This study assessed four different health outcomes (exacerbations, GP consultations, non-specific respiratory events and adverse-medication events), and multiple factors (e.g. inhaler device, inhalertechnique checks) that could influence the impact of this clinical practice. 


\begin{abstract}
Background

Switching inhalers to cheaper equivalent products is often advocated as a necessary cost saving measure, yet the impact on patient's health and healthcare utilisation has not been measured.
\end{abstract}

\title{
Methods
}

We identified asthma and chronic obstructive pulmonary disease (COPD) patients from UK primary care electronic healthcare records between 2000 and 2016. A self-controlled case series was used to estimate incidence rate ratios (IRR); comparing outcome rates during the risk period, 3-months after the exposure (financially-motivated switch), and control periods (pre-switch, and post-risk period). Four outcomes were assessed: disease exacerbation, GP consultation, non-specific respiratory events and adverse-medication events. Medication possession ratio (MPR) was calculated to assess adherence. 2017 NHS indicative prices were used to estimate cost differences per equivalent dose.

\section{Results}

We identified a cohort of 569,901 asthma and 171,231 COPD regular inhaler users, $2 \%$ and $6 \%$ had been switched, respectively. Inhaler switches between a brand-to-generic inhaler, and all other switches (brand-to-brand, generic-to-generic, generic-to-brand), were associated with reduced exacerbations (brand-to-generic: IRR=0.75, 95\% Cl 0.64-0.88; all other: IRR=0.79, 95\% Cl 0.71-0.88). Gender, age, therapeutic class, inhaler device, and inhaler-technique checks did not significantly modify this association $(p<0.05)$. The rate of consultations, respiratory-events and adverse-medication events did not change significantly (consultations: IRR=1.00, 95\% $\mathrm{Cl} 0.99-1.01$; respiratory-events: IRR $=0.96,95 \% \mathrm{Cl}$ 0.95-0.97; adverse-medication-events: IRR=1.05, 95\% Cl 0.96-1.15). Adherence significantly increased post-switch (median MPR: pre-switch=54\%, post-switch=62\%; $p<0.001$ ). Switching patients, in the cohort of regular inhaler users, to the cheapest equivalent inhaler, could have saved around $\mathrm{f} 6$ million annually.

\section{Conclusion}

Switching to an equivalent inhaler in patients with asthma or COPD appeared safe and did not negatively affect patient's health or healthcare utilisation. 


\section{Introduction}

In the UK, over 5.4 million people receive asthma treatment (estimated in 2012), and over 1.2 million people have a COPD diagnosis $(1,2)$. Inhalers incur a large healthcare cost; due to the prevalence of asthma, three of the top five most expensive drugs in the National Health Service (NHS) budget are inhalers. Over $f 1.1$ billion of the NHS budget is spent directly on asthma, the majority of which is due to medication; an additional $f 800$ million is spent directly on COPD.

Pharmaceutical companies have made huge investments in the development of new inhaled medications, resulting in the availability of over 200 different products; expiration of many patents have led to the growth of generic products. Nonetheless, markets become dominated by only a few inhalers, even when cheaper equivalent products are available. Randomised controlled trials have demonstrated that switching inhalers between specified equivalent products results in comparable effectiveness $(3,4)$. However, trials have optimised participant's inhaler technique and encouraged high levels of adherence, which does not reflect everyday clinical practice and most respiratory patients do not meet typical trial eligibility criteria $(5,6)$. There is a paucity of real-world studies assessing health outcomes after switching patients to an equivalent inhaler, furthermore, no study has specifically addressed switching for financial gain(7-11).

In many European countries regulations allow switching of inhalers to cheaper bioequivalent products, generic or branded, including UK, Germany, Italy, Finland and Netherlands; other countries, including Spain, Belgium and Sweden, regulate against it due to the speculated negative impact on patient's health and healthcare utilisation(12). In the UK, many local governments strongly advocate switching to cheaper equivalent inhalers, but the effect of this clinical practice on patient's health and their healthcare use is unknown. Physician opinion appears often to be one of reticence, primarily due to apprehension of the interchangeability of inhalers, although the evidence to support this concern is marginal(13-18). This study aimed to describe the prevalence and health impact of financiallymotivated inhaler switching, for non-clinical motivation, in the UK and the subsequent health impact.

\section{Methods}

\section{Data source}

We used the Clinical Practice Research Database (CPRD), a nationally representative database of deidentified electronic healthcare records. CPRD holds data on diagnoses, symptoms, and prescriptions on more than 11 million patients across the UK(19). Globally, it is one of the largest longitudinal healthcare databases, and has been extensively validated(19). Secondary care and mortality information was obtained from the Hospital Episode Statistics (HES) database and Office of National Statistics (ONS), respectively. HES contains information on all admissions to English NHS hospitals. Approximately $60 \%$ of practices in CPRD have individual level linkage to HES and ONS, and to socioeconomic data (Index of Multiple Deprivation).

\section{Study design}

We conducted a self-controlled case series (SCCS) analyses (Figure 1). SSCS is an increasingly popular study design(20-22), it allows each individual to act as their own control (comparing outcome rates 
during periods of exposure to periods of non-exposure) to therefore implicitly control for confounding factors that do not vary with time. This approach significantly reduces the bias that can occur in observational studies; for example a cohort or case-control could suffer from confounding by indication which would be an issue with this research question. SCCS is also statistically more efficient than traditional cohort and case-control designs. The SCCS method is most suitable when there are acute outcomes (e.g. exacerbation) and transient exposures (e.g. inhaler switch), and that exact timings of these are available(23). Incidence rate ratios (IRR) are calculated, comparing the rate of events during exposed periods (defined as the 'risk period') with that during all other observed periods (defined as the 'control period'). To ensure valid and unbiased estimates, certain assumptions should be met(24). Firstly, the outcome should not affect the occurrence of a further outcome event. As exacerbations are not independent we studied only the first exacerbation outcome(24); therefore, all patients had to have a 12-month exacerbation-free period before entering the SCCS-exacerbation cohort (prior to the control period). The other outcomes were considered to be independent. A second assumption is that the outcome does not affect the probability of exposure. This potential bias is common and simply reduced by using a pre-exposure period that is then not included in the analysis(24). Thirdly, the outcome should not increase the probability of death; the typical approach to deal with this is to carry out a sensitivity analysis excluding patients that died(24).

\section{Study population}

Patients were identified as having asthma or COPD using validated algorithms $(25,26)$.

\section{Study population: regular inhaler users}

Only patients that were on a regular maintenance inhaler were included; this was defined as $\geq 3$ consecutive prescriptions of the same inhaler class, each within 3 months of the next one. Maintenance inhaler classes were inhaled corticosteroid (ICS), long-acting beta agonist (LABA), combination LABA-ICS, long-acting muscarinic antagonist (LAMA), or combination LAMA-LABA. Prescription data was included from the latest date of the following: $1^{\text {st }}$ January 2000, patient's data was research acceptable (CPRD quality control), patient started a continuous CPRD record, $18^{\text {th }}$ birthday (asthma) or $35^{\text {th }}$ birthday (COPD), or first validated asthma/COPD Read code. Follow-up was censored at the earliest date of the following: patient transferred out of CPRD, death, last data collection date, or $31^{\text {st }}$ December 2016.

\section{Main exposure and the four outcomes}

\section{Financially-motivated inhaler switch (main exposure)}

An inhaler switch was defined as at least 3 consecutive prescriptions of the same inhaler, followed by a subsequent prescription of a different inhaler, in the same therapeutic class, each within 3 months of the previous. For the switch to be defined as financially-motivated it must be (a) between the same bioequivalent dosage, (b) occurred on a day without a respiratory symptom or adverse-medication symptom/event, and (c) not on the day of another new inhaler. Switches were further broken down into those between brand-to-generic inhaler (financial motivation was the only objective), all other switches (financial motivation was highly likely). Three months use was arbitrarily defined as the time point by which the switch itself would have impacted on the patient's health as it expected the effect 
of the 'switch' would be reasonably immediate. This was also further broken down by 1-monthly periods to look for any dose affect over time.

\section{Outcomes}

The main outcome of interest was exacerbations. COPD exacerbations were identified using a validated algorithm for CPRD data $(27,28)$. Asthma exacerbations were identified as previously defined(29), a short course of oral corticosteroids, a hospital admission for asthma or death secondary to asthma. The other three outcomes were primary care consultations, non-specific respiratory events (including respiratory symptoms, inhaler technique, and other asthma and COPD specific events; Supplementary Table 1), and adverse-medication events (Supplementary Table 2).

\section{Populations used in the SCCS-cohorts}

The SCCS analysis requires that each included patient should have the outcome (at some point during either the risk or control period), and the exposure - as those without both would not contribute towards the rate ratio estimate (patient exposed but without an outcome would have a rate of zero in all time periods); therefore, four different cohorts were identified for the four different outcomes described above (Figure 2). The SCCS cohorts were: (1) exacerbations, (2) GP consultations, (3) nonspecific respiratory events and (4) adverse-medication events. Study follow-up was a maximum of 2 years. All patients entered the SCCS analysis 12 -months before the non-clinical inhaler switch, and were censored at the earliest date of: 12-months after the inhaler switch, death, transferred out of CPRD, or last data collection. The exacerbation SCCS-cohort only comprised of patients with linked HES/ONS data (to ensure inclusion of hospital treated exacerbations).

\section{Measuring adherence}

Adherence was calculated using the medication possession ratio (MPR); the sum of the days medication was prescribed, divided by the total number of days between the first and the last prescription plus the duration of the last prescription; this number is then expressed as a percentage. MPR was compared between pre-switch (12-months before the switch) and post-switch (from the switch until follow-up ended).

\section{Statistical and sensitivity analyses}

Event rates were compared during the risk period (for 3-months after exposure) and the control periods (11-months before the pre-exposure 1-month period, and from the end of the risk period until censored) (Figure 1). IRRs were also measured for each consecutive 1-month period during the 3month risk period. The exacerbation analysis was stratified by the type of inhaler that was switched between; switches from a branded to a generic inhaler were analysed separately, as these should only be carried out for financial gain. Other scenarios (switches between: generic to branded, branded to branded, or generic to generic) were analysed separately as it is possible some of these switches may have been carried out for an undocumented clinical reason. IRRs were estimated using fixed effects conditional Poisson regression models. The effect was adjusted for age using age bands (years: 18-45, $45-55,55-65,65-75,75-85,85-110)$. Evidence of interaction was assessed using likelihood ratio tests for several time-invariant variables: respiratory condition, gender, therapeutic class, generic/brand switch, device switch, kept/not kept on same inhaler. The effects were reported by stratifying the analysis for each variable. A negative control analysis was also carried out, such that the 'exposure' 
date was a random consecutive inhaler prescription; patients also had to fulfil all eligibility criteria of the SCCS cohort. Stata 14.0 was used for all analysis.

\section{Cost analysis of switching inhalers}

Inhaler prices were obtained using 2017 NHS indicative prices from the NHS Dictionary of Medicines and Devices $(\mathrm{dm}+\mathrm{d})$. All costs were calculated per bioequivalent medication dose. Assumptions about how many inhalers could be switched to generic inhalers used NHS product availability in 2017. Cost differences were based on the inhaler cost only.

\section{Ethical approval}

The protocol for this research was approved by the Independent Scientific Advisory Committee (ISAC) for MHRA Database Research (protocol number 17_090RAR) and the approved protocol was made available to the journal and reviewers during peer review. Generic ethical approval for observational research using CPRD with approval from ISAC has been granted by a Health Research Authority (HRA) Research Ethics Committee (East Midlands - Derby, REC reference number 05/MRE04/87). Linked pseudonymised data was provided for this study by CPRD. Data is linked by NHS Digital, the statutory trusted third party for linking data, using identifiable data held only by NHS Digital. Select practices consent to this process at a practice level with individual patients having the right to opt-out.

\section{Results}

\section{Temporal changes in UK generic and device prescriptions}

There has been a fall in the proportion of generic prescriptions for all therapeutic classes in asthma and COPD; most notable in ICS prescriptions (Supplementary Figure 1). The proportion of dry powder inhaler (DPI) used in asthma dropped from 50\% in 2000 to $30 \%$ in 2016, but remained around $50 \%$ in COPD (Supplementary Figure 2).

\section{Low prevalence of inhaler switching}

Over the last decade the proportion of patient's that had their inhalers switched within the same therapeutic class was low, although it slightly increased over time (2006-2016: asthma $N=569,901,2 \%$ to $6 \%$ switched; COPD N=171,321, 3\% to $10 \%$ switched) (Supplementary Figure 3). Around two-thirds of switches were for non-clinical reasons, the majority were between branded and generic products, and around one-third were for increases in medication dose or adverse-medication effects. Inhaler switching peaks were in 2001 (Becotide, a phased out ICS), 2007/8 (chlorofluorocarbons, phased out MDIs), and 2014 onwards (LAMA and combination LABA-ICS inhalers).

\section{SCCS-cohorts were similar to the regular inhaler users}

Of those with a non-clinical inhaler switch, 5,242 patients met eligibility criteria for the exacerbation SCCS-cohort, 50,289 for the consultations SCCS-cohort, 51,659 for the respiratory events SCCS-cohort and 3,258 for the adverse-medication events SCCS-cohort (Figure 2). The four SCCS-cohorts were broadly similar in characteristics to the populations they were derived from (Table 1). The SCCScohorts were also similar to the much larger population of regular inhaler users (Supplementary Table 
3). The SCCS-cohorts were equivalent in terms of inhalers prescribed, frequency of inhaler technique checks (around $40 \%$ ) and proportion that had experienced adverse-medication events (around $2 \%$ ) (Table 1); except for the adverse-medication events SCCS-cohort, as would be expected.

Most non-clinical inhaler switches occurred with ICS and LABA-ICS. Around $90 \%$ were between an identical drug (Table 1), approximately three-quarters were between the same device type, and around $80 \%$ were between generic and brand. Around $95 \%$ of patients kept the inhaler that they were switched to.

\section{Health impact of non-clinical inhaler switching}

The IRR of an exacerbation was significantly lower after switching (brand-to-generic: crude IRR $=0.74$, $95 \% \mathrm{Cl}$ 0.63-0.87, age-adjusted IRR $=0.75,95 \% \mathrm{Cl} 0.64-0.88$; all other switches: crude IRR $=0.78,95 \% \mathrm{Cl}$ $0.70-0.87$, age-adjusted $=0.79,95 \% \mathrm{Cl} 0.71-0.88$ ). Differences in patient characteristics, or differences in measured factors related to the inhalers, did not significantly modify the rate of exacerbations; these characteristics were differences in patient condition (COPD/asthma), gender, therapeutic class (ICS, LABA-ICS, LABA, LAMA), device switch (MDI/DPI) and inhaler technique check (LRT p >0.05, Tables 2 \& 3). Exacerbation rates were not significantly different each consecutive month of the three months after the inhaler switch ( $p<0.05$, Supplementary Tables $4 \& 5)$. A sensitivity analysis excluding patients who died $(\mathrm{N}=80)$ showed negligible difference in the IRRs.

There was no significant association between the rate of consultations and switching (age-adjusted IRR $=1.00,95 \% \mathrm{Cl}$ 0.99-1.01; Table 4. There was a very slight reduction in respiratory events (ageadjusted IRR=0.96, 95\% $\mathrm{Cl} 0.94-0.97)$. There was a non-significant minor increase in the risk of adverse events (age-adjusted IRR=1.05, 95\% $\mathrm{Cl} 0.96-1.15$ ); the risk decreased with each consecutive month, during the 3-month risk period (Supplementary Table 6).

The negative control analyses found no effect on exacerbations (age-adjusted IRR $=0.99,95 \% \mathrm{Cl} 0.96$ 1.02).

\section{Impact of switching on adherence}

Inhaler adherence improved after the inhaler switch. The median MPR (IQR) for the 12 months preinhaler switch was $54.8 \%$ (39.1-78.2), compared to $62.6 \%$ post-inhaler switch $(47.0-93.9)(p<0.001)$. Post-inhaler switch adherence was not different between patients that were switched on the day of a GP consultation or not (median MPR $=62.6 \%, p>0.05$ ).

\section{Potential cost saving of switching to cheaper inhalers}

In the exacerbation SCCS cohort, 1,184 of the 5,242 switches (23\%) could have been switched to a cheaper equivalent generic product in 2017 . This could have saved an estimated $£ 14,308$, or annual saving of around $£ 172,000$ (assuming an inhaler prescribed per month) (Supplementary Table 7). In the same cohort, 2,125 of the 5,242 switches (41\%) could have been switched to a cheaper bioequivalent branded product (same therapeutic class and bioequivalent dose, although drug may differ). This could have saved $£ 28,231$, or annual saving of around $£ 339,000$ (Supplementary Table 8).

In the total cohort of 665,105 regular inhaler users, there was an alternative cheaper equivalent generic inhaler available for $28 \%$ of prescriptions (LABA-ICS or LAMA) in 2016; switching to these could 
have saved approximately $£ 1.97$ million. An estimated additional $£ 4.1$ million could have been saved if all inhalers had been switched to the cheapest bioequivalent product (including generic or branded products), assuming all patients were suitable for switching to the alternative.

CPRD represents at least $5 \%$ of the UK population, extrapolating our findings indicates that, if implemented across the UK, switching to the cheapest available bioequivalent product (generic or branded), could have saved the NHS approximately $f 112$ million (1.5\% of the total primary care annual prescribing costs). 


\section{Discussion}

\section{Principal findings}

From this study of over 0.65 million asthma patients and just under 0.2 million COPD patients, it was observed that inhaler switching for financial-motivation was uncommon; in keeping with the only other nationally representative study of inhaler switching(7). The increase in switches from generic to branded inhalers is likely due to the increase in the availability of cheaper branded inhalers in the UK; the cheapest LABA-ICS in 2017 was a branded inhaler. We found that switching slightly reduced the risk of an exacerbation. This risk was not significantly affected by the patient's age, gender, type of respiratory disease, whether the switch was between MDI/DPI devices or not, whether the patient had a documented inhaler check that year, or the medication class that was switched. Around $95 \%$ of the patients remained on their switched inhaler. Interestingly, adherence to the switched inhaler was significantly higher than adherence to the pre-switch equivalent inhaler. This may partially explain the observed reduction in exacerbations as, although the study was not designed to measure adherence as a primary outcome, the increase was only slightly below the considered clinically minimal important difference of $10 \%$ (30). Further analyses, of over 50,000 patients, showed that non-clinical inhaler switching did not affect the rate of GP consultations, but slightly decreased the rate of non-specific respiratory events (including symptoms) and slightly increased the rate of adverse medication events, however, these effects were not statistically significant. Overall this clinical practice appears to occur infrequently in the UK. The cost analyses estimated significant savings could potentially be gained from switching expensive popular inhalers to bioequivalent cheaper (generic or branded) ones.

A less commonly advocated, but arguably as important, reason to switch an inhaler, is to reduce the large environmental impact that MDI inhalers produce (31). Hydrofluorocarbon inhalers are estimated to contribute $4 \%$ of the NHS's entire carbon footprint, with MDIs identified as a 'carbon hotspot' in the NHS (32). Switching from a MDI to a DPI is thought to decrease the carbon footprint by a factor of 18 (31). Discerningly, our observations suggest only around a third of inhalers prescribed for asthma patients, and half of those prescribed for COPD patients, are DPIs; yet switching between MDIs and DPIs did not seemingly impact on exacerbations, adverse medication events or respiratory events.

\section{Comparison to previous studies}

There have been few real-world studies addressing switching inhaler therapy of equivalent medication and dose. A small UK asthma study, 1993-2003, looked at ICS switching of 824 patients, at GP practicelevel, not individual-level; they found no change in exacerbations (11). Another UK study, considered 979 asthma patients, switching from any ICS to a particular inhaler, the reason was not reported and may have often been clinical; they found no worsening of clinical outcomes (8). A more recent observational UK study addressed switching of 382 asthma patients from one commonly used LABAICS inhaler to the cheapest one (10). Although the product drugs differed, the study found a decline in exacerbations, improvement in asthma control, and reduction in healthcare costs; however, the reason for the switches was not described, and due to the design there may have been confounding by indication. One large Dutch study, including 70,053 patients, investigated adherence to inhaler medication after switching to generic products; this study found an increase in adherence in patients switched between a branded to a generic inhaler (7). Our findings in respect to adherence levels are also in keeping with previous studies (7,33). Evidence is even sparser for COPD patients (15), with only a small retrospective Japanese observational study of 57 patients that had switched between specific 
LAMA inhalers (9). None of these studies comprehensively addressed the overall impact of non-clinical inhaler switching, nor directly examined the impact of switching from a branded to a generic inhaler.

\section{Strengths and weaknesses of the study}

One advantage was the use of real-world data; whereas in most trials, inhaler technique is optimised, and adherence is encouraged. The SCCS cohorts were similar to the large nationally representative population that they were drawn from. Therefore, these two features provide results likely to be generalisable to the UK, and other similar populations. However, it is also probable that most patients were only switched if deemed appropriate by their GP practice, therefore, these results would only be generalisable to such patients. Switching may also have led to improved adherence and/or inhaler technique if the GP practice or patient's pharmacist provided education at the time of the switch.

Another advantage was that the SCCS design is less prone to confounding and statistically more efficient than traditional cohort designs. To prevent violation of the SCCS assumptions, in the exacerbation cohort alone, an eligibility criteria of a 12-month period of no exacerbations prior to the observation period was set. This could have reduced generalisability (as a patient must have 1-year exacerbation-free period), but, the SCCS-exacerbation cohort was very similar to the reference population and analyses with the three other outcomes, which did not have this eligibility stipulation, showed comparable findings. It's also possible that the effect of inhaler switching had a shorter or more prolonged affect than 3 months, however, this would only have underestimated the relative risk. Although the prescription data quality was high, we did not know if the prescription was dispensed or taken. However, a very low proportion did not stay on the switched prescription (suggesting the medication was dispensed). The respiratory and adverse-medication events measured were only those that were recorded, potentially some were not. If such under recording was equally likely throughout follow-up, this would only lead to reduced power, rather than generating a biased estimate. Mild exacerbations were not included as an outcome as identifying these from the data would not have been accurate. However, the assessment of symptom changes, should have identified milder clinical effects. The potential cost savings, depended on the assumption that all patients were suitable; but, we recognize this is unlikely as not all inhaler devices suit everyone. The cost analysis did not take into account savings from reductions in exacerbations. Since 2016 it is possible switching prevalence has changed, although this would not affect the effect estimates from switching.

\section{Implications of these findings}

Treatment with combination inhalers is increasing; as these are some of the most expensive products, this will continue the escalation in respiratory spending. Our findings suggest that financially-driven inhaler switching occurs infrequently. This is likely due to physician reticence, related to concern that switching is detrimental to a patient's health. This apprehension has been discussed in several reviews, and questionnaires found that doctors across Europe believe that inhalers are not interchangeable(12-14,16-18,34-37). Reassuringly, we have shown here, that exacerbations, respiratory symptoms, and adverse-medication events did not increase; in fact, only $5 \%$ of patients did not stay on their new inhaler. We propose that the temporary decrease in exacerbations could be related to a temporary increase in inhaler adherence, due to intensified medication awareness or related to adherence discussion at the time of the inhaler switch. There may have been, predictable or unpredictable, reasons why inhaler switching was successful in these patients, but the parameters we were able to consider did not reveal any influencing characteristics. Further studies are therefore 
needed to determine the factors that will ensure a successful outcome, and which patients and circumstances are not suitable.

These findings have important implications and could help inform national policy; they suggest that switching inhalers is safe, if implemented correctly (which should include appropriate patient selection and mandating the importance of providing inhaler education), and could help to re-direct the respiratory healthcare budget towards more effective use.

\section{Statements}

\section{Funding}

There is no funding to report.

\section{Contributors}

All authors provided substantial contributions to the work. CID, ID, LS and JKQ devised the study. CIB analysed, interpreted the data and produced draft manuscripts. ID, JO and DG provided specific input for the analysis and interpretation. All authors reviewed and edited the manuscript. All were happy with the final version and approved it for submission for publication.

\section{Exclusive licence}

I, the Submitting Author has the right to grant and does grant on behalf of all authors of the Work (as defined in the below author licence), an exclusive licence and/or a non-exclusive licence for contributions from authors who are: i) UK Crown employees; ii) where BMJ has agreed a CC-BY licence shall apply, and/or iii) in accordance with the terms applicable for US Federal Government officers or employees acting as part of their official duties; on a worldwide, perpetual, irrevocable, royalty-free basis to BMJ Publishing Group Ltd ("BMJ") its licensees and where the relevant Journal is co-owned by BMJ to the co-owners of the Journal, to publish the Work in Thorax and any other BMJ products and to exploit all rights, as set out in our licence.

The Submitting Author accepts and understands that any supply made under these terms is made by BMJ to the Submitting Author unless you are acting as an employee on behalf of your employer or a postgraduate student of an affiliated institution which is paying any applicable article publishing charge ("APC") for Open Access articles. Where the Submitting Author wishes to make the Work available on an Open Access basis (and intends to pay the relevant APC), the terms of reuse of such Open Access shall be governed by a Creative Commons licence - details of these licences and which Creative Commons licence will apply to this Work are set out in our licence referred to above.

I am one author signing on behalf of all co-authors of the Work.

\section{Competing interests}

CIB reports from outside the submitted work grants from AstraZeneca, Chiesi and Asthma UK. ID reports grants from GlaxoSmithKline and British Pharmaceutical Industry outside the submitted work. GD reports personal fees from outside the submitted work from AstraZeneca, Boehringer 
Ingelheim, Chiesi, GSK, Pfizer, Napp, Novartis and Teva. JKQ reports from outside the submitted work: grants from The Health Foundation, MRC, British Lung Foundation and Asthma UK; grants and personal fees from GSK, AstraZeneca, Boehringer Ingelheim, Insmed, Bayer, Chiesi and IQVIA; personal fees from Teva. LS reports outside the submitted work, grants from Wellcome, MRC, NIHR, British Heart Foundation, Diabetes UK, grants and personal fees from GSK, and is a Trustee of the British Heart Foundation. JO does not report any competing interests.

\section{References}

1. Snell N, Strachan D, Hubbard R, Gibson J, Gruffydd-Jones K, Jarrold I. S32 Epidemiology of chronic obstructive pulmonary disease (COPD) in the uk: findings from the british lung foundation's 'respiratory health of the nation' project. Thorax. 2016 Dec 1;71(Suppl 3):A20.1A20.

2. National Institute for Health and Care Excellence. Quality standard for asthma. 2013.

3. Wise RA, Anzueto A, Cotton D, Dahl R, Devins T, Disse B, et al. Tiotropium Respimat Inhaler and the Risk of Death in COPD. N Engl J Med. 2013 Oct 17;369(16):1491-501.

4. Lasserson TJ, Ferrara G, Casali L. Combination fluticasone and salmeterol versus fixed dose combination budesonide and formoterol for chronic asthma in adults and children. Cochrane database Syst Rev. 2011 Dec 7;(12):CD004106.

5. Travers J, Marsh S, Williams M, Weatherall M, Caldwell B, Shirtcliffe P, et al. External validity of randomised controlled trials in asthma: to whom do the results of the trials apply? Thorax. 2007 Mar;62(3):219-23.

6. Travers J, Marsh S, Caldwell B, Williams M, Aldington S, Weatherall M, et al. External validity of randomized controlled trials in COPD. Respir Med. 2007 Jun;101(6):1313-20.

7. Engelkes M, van Blijderveen JC, Overbeek JA, Kuiper J, Herings RCM, Sturkenboom MCJM, et al. Brand and generic use of inhalation medication and frequency of switching in children and adults: A population-based cohort study. J Asthma. 2017 Nov 29;1-9.

8. King C, Price D, Thomas V, von Ziegenweidt J, Gould S, Hutton C. Switching patients from other inhaled corticosteroid devices to the Easyhaler: historical, matched-cohort study of real-life asthma patients. J Asthma Allergy. 2014 Apr;7:31.

9. Hanada S, Wada S, Ohno T, Sawaguchi H, Muraki M, Tohda Y. Questionnaire on switching from the tiotropium HandiHaler to the Respimat inhaler in patients with chronic obstructive pulmonary disease: changes in handling and preferences immediately and several years after the switch. Int J Chron Obstruct Pulmon Dis. 2015;10:69-77.

10. Price D, Small I, Haughney J, Ryan D, Gruffydd-Jones K, Lavorini F, et al. Clinical and cost effectiveness of switching asthma patients from fluticasone-salmeterol to extra-fine particle beclometasone-formoterol: a retrospective matched observational study of real-world patients. Prim Care Respir J. 2013 Dec 2;22(4):439-48.

11. Thomas M, Price D, Chrystyn H, Lloyd A, Williams AE, von Ziegenweidt J. Inhaled corticosteroids for asthma: impact of practice level device switching on asthma control. BMC 
Pulm Med. 2009 Dec 2;9(1):1.

12. Lavorini F, Ninane V, Haughney J, Bjermer L, Molimard M, Dekhuijzen RP. Switching from branded to generic inhaled medications: potential impact on asthma and COPD. Expert Opin Drug Deliv. 2013 Dec 14;10(12):1597-602.

13. Price D. Do healthcare professionals think that dry powder inhalers can be used interchangeably? Int J Clin Pract. 2005 Nov 8;59(149):26-9.

14. Capstick T, Khachi H, Murphy A, D’Ancona G, Meynell H, Wilson P. Generic prescribing is not appropriate for inhaled drugs. Pharm J. 2015;8 Jan.

15. Braido F, Lavorini F, Blasi F, Baiardini I, Canonica GW. Switching treatments in COPD: implications for costs and treatment adherence. Int J Chron Obstruct Pulmon Dis. 2015;10:2601-8.

16. Booker R. Do patients think that dry powder inhalers can be used interchangeably? Int J Clin Pract. 2005 Nov 8;59(149):30-2.

17. Bjermer $L$. The importance of continuity in inhaler device choice for asthma and chronic obstructive pulmonary disease. Respiration. 2014;88(4):346-52.

18. Björnsdóttir US, Gizurarson S, Sabale U. Potential negative consequences of non-consented switch of inhaled medications and devices in asthma patients. Int J Clin Pract. 2013 Sep;67(9):904-10.

19. Herrett E, Gallagher AM, Bhaskaran K, Forbes H, Mathur R, Staa T van, et al. Data Resource Profile: Clinical Practice Research Datalink (CPRD). Int J Epidemiol. 2015;44(3):827-36.

20. Shin J-Y, Roughead EE, Park B-J, Pratt NL. Cardiovascular safety of methylphenidate among children and young people with attention-deficit/hyperactivity disorder (ADHD): nationwide self controlled case series study. BMJ. 2016 May 31;353:i2550.

21. Warren-Gash C, Blackburn R, Whitaker H, Hayward A. Respiratory infections as vascular triggers: self-controlled case series analysis of linked Scottish data. Lancet. 2017 Feb 23;389:S101.

22. Kwong JC, Schwartz KL, Campitelli MA, Chung H, Crowcroft NS, Karnauchow T, et al. Acute Myocardial Infarction after Laboratory-Confirmed Influenza Infection. N Engl J Med. 2018 Jan 25;378(4):345-53.

23. Whitaker HJ, Farrington $\mathrm{CP}$, Spiessens $\mathrm{B}$, Musonda P. Tutorial in biostatistics: the selfcontrolled case series method. Stat Med. 2006 May 30;25(10):1768-97.

24. Petersen I, Douglas I, Whitaker H. Self controlled case series methods: an alternative to standard epidemiological study designs. BMJ. 2016 Sep 12;i4515.

25. Nissen F, Morales DR, Mullerova H, Smeeth L, Douglas IJ, Quint JK. Validation of asthma recording in the Clinical Practice Research Datalink (CPRD). BMJ Open. 2017 Aug 11;7(8):e017474.

26. Quint JK, Mullerova H, DiSantostefano RL, Forbes H, Eaton S, Hurst JR, et al. Validation of chronic obstructive pulmonary disease recording in the Clinical Practice Research Datalink (CPRD-GOLD). BMJ Open. 2014 Jul 23;4(7):e005540-e005540.

27. Rothnie KJ, Müllerová H, Hurst JR, Smeeth L, Davis K, Thomas SL, et al. Validation of the 
Recording of Acute Exacerbations of COPD in UK Primary Care Electronic Healthcare Records. PLoS One. 2016;11(3):e0151357.

28. Rothnie KJ, Müllerová H, Thomas SL, Chandan JS, Smeeth L, Hurst JR, et al. Recording of hospitalizations for acute exacerbations of COPD in UK electronic health care records. Clin Epidemiol. 2016 Nov;8:771-82.

29. Bloom Cl, Nissen F, Douglas IJ, Smeeth L, Cullinan P, Quint JK. Exacerbation risk and characterisation of the UK's asthma population from infants to old age. Thorax. 2017 Oct 26;thoraxjnl-2017-210650.

30. Hess LM, Raebel MA, Conner DA, Malone DC. Measurement of Adherence in Pharmacy Administrative Databases: A Proposal for Standard Definitions and Preferred Measures. Ann Pharmacother. $2006 \mathrm{Jul}$ 4;40(7-8):1280-8.

31. Hillman T, Mortimer F, Hopkinson NS. Inhaled drugs and global warming: time to shift to dry powder inhalers. BMJ. 2013 May 28;346:f3359.

32. UK Progress on reducing F-gas Emissions - Environmental Audit Committee - House of Commons. Parliamentary Business. 2018.

33. Engelkes M, Janssens HM, De Jongste JC, Sturkenboom MCJM, Verhamme KMC, Respir E. Medication adherence and the risk of severe asthma exacerbations: a systematic review. Eur Respir J. 2014;

34. Williams AE, Chrystyn H. Survey of pharmacists' attitudes towards interchangeable use of dry powder inhalers. Pharm World Sci. 2007 May 23;29(3):221-7.

35. Desai RJ, Sarpatwari A, Dejene S, Khan NF, Lii J, Rogers JR, et al. Differences in rates of switchbacks after switching from branded to authorized generic and branded to generic drug products: cohort study. BMJ. 2018 Apr 3;361:k1180.

36. Braido F, Lavorini F, Blasi F, Baiardini I, Walter Canonica G. Switching treatments in COPD: implications for costs and treatment adherence. Int J COPD. 2015;10:2601-8.

37. Doyle S, Lloyd A, Williams A, Chrystyn H, Moffat M, Thomas M, et al. What happens to patients who have their asthma device switched without their consent? Prim Care Respir J. 2010 Feb 19;19(2):131-9. 
Table 1. Description of the demographics and characteristics of each of the SCCS cohorts, and the study population of patients that they were drawn from.

\begin{tabular}{|c|c|c|c|c|c|c|c|c|c|c|c|c|}
\hline & \multicolumn{2}{|c|}{$\begin{array}{l}\text { Exacerbation } \\
\text { cohort }\end{array}$} & \multicolumn{2}{|c|}{$\begin{array}{l}\text { All non-clinical } \\
\text { switchers } \\
\text { HES linked }\end{array}$} & \multicolumn{2}{|c|}{$\begin{array}{l}\text { Non-urgent } \\
\text { GP consults } \\
\text { cohort }\end{array}$} & \multicolumn{2}{|c|}{$\begin{array}{l}\text { Respiratory } \\
\text { events cohort }\end{array}$} & \multicolumn{2}{|c|}{$\begin{array}{c}\text { Adverse } \\
\text { inhaler events } \\
\text { cohort }\end{array}$} & \multicolumn{2}{|c|}{$\begin{array}{l}\text { All non-clinical } \\
\text { switchers }\end{array}$} \\
\hline & $\mathbf{N}$ & $\%$ & $\mathbf{N}$ & $\%$ & $\mathbf{N}$ & $\%$ & $\mathbf{N}$ & $\%$ & $\mathbf{N}$ & $\%$ & $\mathbf{N}$ & $\%$ \\
\hline Total & 5,242 & 100 & 23,488 & 100 & 50,289 & 100 & 51,659 & 100 & 3,258 & 100 & 69,812 & 100 \\
\hline \multicolumn{13}{|l|}{ Patient Characteristics } \\
\hline \multicolumn{13}{|l|}{ Respiratory condition } \\
\hline Asthma & 4,232 & 80.7 & 18,185 & 77.4 & 43,653 & 86.8 & 45,318 & 87.7 & 2821 & 86.6 & 59,909 & 85.8 \\
\hline COPD & 1,010 & 19.3 & 5,303 & 22.6 & 6,636 & 13.2 & 6,341 & 12.3 & 437 & 13.4 & 9,903 & 14.2 \\
\hline \multicolumn{13}{|l|}{ Gender } \\
\hline Male & 2,377 & 45.3 & 10,663 & 45.4 & 21,613 & 43.0 & 21,848 & 42.3 & 1190 & 36.5 & 29,925 & 42.9 \\
\hline Female & 2,865 & 54.7 & 12,825 & 54.6 & 28,676 & 57.0 & 29,811 & 57.7 & 2068 & 63.5 & 39,887 & 57.1 \\
\hline $\begin{array}{l}\text { Age at switch, } \\
\text { years (median, IQR) }\end{array}$ & \multicolumn{2}{|c|}{$68.2(58-76)$} & \multicolumn{2}{|c|}{$69.6(62-77)$} & \multicolumn{2}{|c|}{$63.6(50-73)$} & \multicolumn{2}{|c|}{$63.4(50-73)$} & \multicolumn{2}{|c|}{$67.0(57-75)$} & \multicolumn{2}{|c|}{$62.7(49-73)$} \\
\hline \multicolumn{13}{|l|}{ IMD } \\
\hline 1 (least deprived) & 597 & 11.4 & 2,663 & 11.3 & 3,829 & 13.6 & 3,733 & 13.3 & 177 & 10.2 & 5,085 & 13.5 \\
\hline 2 & 1,018 & 19.4 & 4,557 & 19.4 & 5,010 & 17.8 & 5,184 & 18.5 & 372 & 21.4 & 7,114 & 18.9 \\
\hline 3 & 1,011 & 19.3 & 4,689 & 20.0 & 5,292 & 18.8 & 5,217 & 18.6 & 268 & 15.4 & 7,245 & 19.2 \\
\hline 4 & 1,147 & 21.9 & 4,998 & 21.3 & 5,813 & 20.7 & 5,957 & 21.2 & 356 & 20.4 & 7,751 & 20.5 \\
\hline 5 & 1,469 & 28.0 & 6,581 & 28.0 & 8,158 & 29.0 & 7,987 & 28.4 & 569 & 32.7 & 10,544 & 27.9 \\
\hline \multicolumn{13}{|l|}{ Smoking } \\
\hline Never & 1,281 & 24.4 & 6,104 & 26.0 & 10,923 & 21.7 & 11,860 & 23.0 & 686 & 21.1 & 16,264 & 23.3 \\
\hline Ex-smoker & 2,678 & 51.1 & 5,916 & 25.2 & 14,382 & 28.6 & 14,219 & 27.5 & 884 & 27.1 & 19,288 & 27.6 \\
\hline Current & 1,283 & 24.5 & 11,468 & 48.8 & 24,984 & 49.7 & 25,580 & 49.5 & 1,688 & 51.8 & 34,260 & 49.1 \\
\hline \multicolumn{13}{|l|}{ COPD, inhaler use pre-switch } \\
\hline ICS alone & 119 & 11.8 & 764 & 14.4 & 822 & 12.4 & 748 & 11.8 & 41 & 9.4 & 1,291 & 13.0 \\
\hline LABA alone & 23 & 2.3 & 91 & 1.7 & 117 & 1.8 & 103 & 1.6 & 3 & 0.7 & 180 & 1.8 \\
\hline LAMA alone & 63 & 6.2 & 481 & 9.1 & 537 & 8.1 & 515 & 8.1 & 23 & 5.3 & 971 & 9.8 \\
\hline LABA \& ICS & 219 & 21.7 & 1,165 & 22.0 & 1,382 & 20.8 & 1,296 & 20.4 & 90 & 20.6 & 2,029 & 20.5 \\
\hline LABA \& LAMA & 17 & 1.7 & 137 & 2.6 & 164 & 2.5 & 162 & 2.6 & 12 & 2.7 & 259 & 2.6 \\
\hline LAMA \& ICS & 41 & 4.1 & 1,165 & 22.0 & 267 & 4.0 & 264 & 4.2 & 25 & 5.7 & 363 & 3.7 \\
\hline Triple therapy & 528 & 52.3 & 2,464 & 46.5 & 3,347 & 50.4 & 3,253 & 51.3 & 243 & 55.6 & 4,810 & 48.6 \\
\hline \multicolumn{13}{|l|}{$\begin{array}{l}\text { Asthma, inhaler use pre- } \\
\text { switch }\end{array}$} \\
\hline ICS only & 1,374 & 32.5 & 6,466 & 35.6 & 16,069 & 36.8 & 16,473 & 36.3 & 829 & 29.4 & 21,847 & 31.3 \\
\hline ICS \& LABA & 1,710 & 40.4 & 6,946 & 38.2 & 17,992 & 41.2 & 18,997 & 41.9 & 1157 & 41.0 & 25,519 & 36.6 \\
\hline ICS \& LABA \& Add on* & 1,020 & 24.1 & 4,264 & 23.4 & 8,615 & 19.7 & 8,856 & 19.5 & 770 & 27.3 & 11,335 & 16.2 \\
\hline Non-guideline treatment & 128 & 3.0 & 509 & 2.8 & 977 & 2.2 & 992 & 2.2 & 65 & 2.3 & 1,208 & 1.7 \\
\hline \multicolumn{13}{|l|}{ Inhaler technique checked^ } \\
\hline Yes & 2,003 & 38.2 & 7,867 & 33.5 & 19,010 & 37.8 & 21,341 & 41.3 & 1369 & 42.0 & 25,025 & 35.8 \\
\hline No & 3,239 & 61.8 & 15,621 & 66.5 & 31,279 & 62.2 & 30,318 & 58.7 & 1889 & 58.0 & 44,787 & 64.2 \\
\hline \multicolumn{13}{|l|}{ Adverse medication events^ } \\
\hline Yes & 135 & 2.6 & 676 & 2.9 & 1,335 & 2.7 & 1,567 & 3.0 & 1435 & 44.0 & 1,975 & 2.8 \\
\hline
\end{tabular}




\begin{tabular}{|c|c|c|c|c|c|c|c|c|c|c|c|c|}
\hline No & 5,107 & 97.4 & 22,812 & 97.1 & 48,954 & 97.3 & 50,092 & 97.0 & 1823 & 56.0 & 67,837 & 97.2 \\
\hline \multicolumn{13}{|c|}{ Inhaler switch characteristics } \\
\hline \multicolumn{13}{|l|}{ Drug class } \\
\hline ICS & 2,164 & 41.3 & 9,928 & 42.3 & 22,138 & 44.0 & 22,624 & 43.8 & 1353 & 41.5 & 30,053 & 43.0 \\
\hline LABA & 377 & 7.2 & 1,629 & 6.9 & 3,411 & 6.8 & 3,189 & 6.2 & 225 & 6.9 & 4,881 & 7.0 \\
\hline LABA/ICS & 1,850 & 35.3 & 7,926 & 33.7 & 19,244 & 38.3 & 20,441 & 39.6 & 1279 & 39.3 & 27,118 & 38.8 \\
\hline LAMA & 851 & 16.2 & 4,005 & 17.1 & 5,496 & 10.9 & 5,406 & 10.5 & 401 & 12.3 & 7,760 & 11.1 \\
\hline \multicolumn{13}{|c|}{ Switch between same drug(s) } \\
\hline No & 540 & 10.3 & 2,413 & 10.3 & 6,169 & 12.3 & 6,443 & 12.5 & 416 & 12.8 & 8,731 & 12.5 \\
\hline Yes & 4,702 & 89.7 & 21,075 & 89.7 & 44,119 & 87.7 & 45,215 & 87.5 & 2841 & 87.2 & 61,083 & 87.5 \\
\hline \multicolumn{13}{|l|}{ Type } \\
\hline Brand to generic & 1,719 & 32.8 & 9,517 & 40.5 & 20,411 & 40.6 & 20,376 & 39.4 & 1411 & 43.3 & 27,111 & 38.8 \\
\hline Generic to generic & 274 & 5.2 & 1,186 & 5.0 & 2,590 & 5.2 & 2,634 & 5.1 & 169 & 5.2 & 3,722 & 5.3 \\
\hline Generic to brand & 2,433 & 46.4 & 9,739 & 41.5 & 20,626 & 41.0 & 21,654 & 41.9 & 1258 & 38.6 & 29,086 & 41.7 \\
\hline Brand to brand & 816 & 15.6 & 3,037 & 12.9 & 6,662 & 13.2 & 6,995 & 13.5 & 420 & 12.9 & 9,893 & 14.2 \\
\hline \multicolumn{13}{|l|}{ Device } \\
\hline MDI to DPI & 411 & 10.1 & 1,973 & 11.2 & 3,884 & 10.3 & 3,948 & 10.2 & 279 & 11.0 & 5,170 & 9.7 \\
\hline DPI to DPI & 1,418 & 34.7 & 7,101 & 40.5 & 14,209 & 37.6 & 14,291 & 36.9 & 890 & 35.2 & 20,493 & 38.6 \\
\hline DPI to MDI & 601 & 14.7 & 2,408 & 13.7 & 5,317 & 14.1 & 5,529 & 14.3 & 348 & 13.8 & 7,398 & 13.9 \\
\hline $\mathrm{MDI}$ to $\mathrm{MDI}$ & 1,655 & 40.5 & 6,058 & 34.5 & 14,381 & 38.1 & 15,013 & 38.7 & 1012 & 40.0 & 20,058 & 37.8 \\
\hline \multicolumn{13}{|l|}{ Kept new inhaler } \\
\hline Yes & 5,015 & 95.7 & 22,135 & 94.2 & 47,486 & 94.4 & 48,795 & 94.5 & 3042 & 93.4 & 65,947 & 94.5 \\
\hline No & 227 & 4.3 & 1,353 & 5.8 & 2,803 & 5.6 & 2,864 & 5.5 & 215 & 6.6 & 3,865 & 5.5 \\
\hline
\end{tabular}

*Add on therapy included a LAMA, leukotriene receptor antagonist or slow release theophylline. COPD= chronic obstructive pulmonary disease. ICS=inhaled corticosteroid. LABA=long-acting beta agonist.

LAMA=long-acting muscarinic antagonist. $\mathrm{MDI}=$ metered-dose inhaler. $\mathrm{DPI}=$ dry powdered inhaler. 
Table 2. Age-adjusted incidence rate ratios of exacerbations, in the 3-month risk period after a brand-to-generic inhaler switch, compared to stable periods.

\begin{tabular}{|c|c|c|c|c|c|c|}
\hline & $\begin{array}{l}\text { Patients } \\
\text { (N) }\end{array}$ & $\begin{array}{l}\text { Exacerbations } \\
\text { in risk period }\end{array}$ & $\begin{array}{l}\text { Exacerbations } \\
\text { in } \\
\text { control period }\end{array}$ & IRR & $95 \% \mathrm{Cl}$ & \\
\hline 3-month risk period & 1719 & 168 & 1483 & 0.75 & $0.64-0.88$ & \\
\hline $\begin{array}{l}\text { Variable association may be } \\
\text { modified by }\end{array}$ & $\begin{array}{l}\text { Patients } \\
\text { (N) }\end{array}$ & $\begin{array}{l}\text { Exacerbations } \\
\text { in risk period }\end{array}$ & $\begin{array}{l}\text { Exacerbations } \\
\text { in } \\
\text { control period }\end{array}$ & IRR & $95 \% \mathrm{Cl}$ & p-value* \\
\hline Disease & & & & & & 0.09 \\
\hline COPD & 332 & 41 & 332 & 0.78 & $0.57-1.09$ & \\
\hline Asthma & 1,151 & 127 & 1151 & 0.74 & $0.61-0.89$ & \\
\hline Gender & & & & & & 0.22 \\
\hline Male & 809 & 88 & 693 & 0.85 & $0.68-1.06$ & \\
\hline Female & 910 & 80 & 790 & 0.67 & $0.53-0.84$ & \\
\hline Medication class switched & & & & & & 0.12 \\
\hline ICS & 363 & 35 & 314 & 0.76 & $0.53-1.07$ & \\
\hline LABA & 182 & 18 & 160 & 0.77 & $0.47-1.27$ & \\
\hline LABA-ICS & 826 & 67 & 722 & 0.61 & $0.48-0.78$ & \\
\hline LAMA & 348 & 48 & 287 & 1.10 & $0.80-1.48$ & \\
\hline Switch between MDI \& DPI & & & & & & 0.61 \\
\hline Yes & 311 & 263 & 121 & 0.85 & $0.60-1.22$ & \\
\hline No & 1,239 & 34 & 1074 & 0.75 & $0.62-0.90$ & \\
\hline Inhaler check in prior year & & & & & & 0.22 \\
\hline Yes & 606 & 535 & 117 & 0.64 & $0.47-0.85$ & \\
\hline No & 1113 & 948 & 51 & 0.81 & 0.67-0.99 & \\
\hline
\end{tabular}

COPD= chronic obstructive pulmonary disease. ICS=inhaled corticosteroid. $L A B A=$ long-acting beta agonist. LAMA=long-acting muscarinic antagonist. 
Table 3. Age-adjusted incidence rate ratios of exacerbations, in the risk period compared to stable periods, after an inhaler switch (brand-to-brand, generic-to-generic or generic-to-brand).

\begin{tabular}{|c|c|c|c|c|c|c|}
\hline & $\begin{array}{l}\text { Patients } \\
\text { (N) }\end{array}$ & $\begin{array}{l}\text { Exacerbations } \\
\text { in risk period }\end{array}$ & $\begin{array}{l}\text { Exacerbations in } \\
\text { control period }\end{array}$ & IRR & $95 \% \mathrm{Cl}$ & \\
\hline 3-month risk period & 3,523 & 362 & 2980 & 0.79 & $0.71-0.88$ & \\
\hline $\begin{array}{l}\text { Variable association may } \\
\text { be modified by }\end{array}$ & $\begin{array}{l}\text { Patients } \\
\text { (N) }\end{array}$ & $\begin{array}{l}\text { Exacerbations } \\
\text { in risk period }\end{array}$ & $\begin{array}{l}\text { Exacerbations in } \\
\text { control period }\end{array}$ & IRR & $95 \% \mathrm{Cl}$ & p-value* \\
\hline Disease & & & & & & 0.09 \\
\hline COPD & 625 & 55 & 534 & 0.64 & $0.48-0.85$ & \\
\hline Asthma & 2,898 & 307 & 2446 & 0.82 & $0.73-0.93$ & \\
\hline Gender & & & & & & 0.48 \\
\hline Male & 1,568 & 155 & 1338 & 0.75 & $0.63-0.89$ & \\
\hline Female & 1,955 & 207 & 1642 & 0.82 & $0.71-0.95$ & \\
\hline Medication class switched & & & & & & 0.20 \\
\hline ICS & 1,801 & 200 & 1522 & 0.87 & $0.75-1.00$ & \\
\hline LABA & 195 & 18 & 170 & 0.73 & $0.45-1.20$ & \\
\hline LABA-ICS & 1,024 & 97 & 860 & 0.72 & $0.58-0.89$ & \\
\hline LAMA & 503 & 47 & 428 & 0.70 & $0.52-0.95$ & \\
\hline Switch: generic/ branded & & & & & & 0.35 \\
\hline Generic to brand & 274 & 247 & 2071 & 0.78 & $0.68-0.89$ & \\
\hline Generic to generic & 2,433 & 23 & 236 & 0.61 & $0.39-0.94$ & \\
\hline Brand to brand & 816 & 92 & 673 & 0.87 & $0.70-1.09$ & \\
\hline Switch between MDI \& DPI & & & & & & 0.11 \\
\hline Yes & 918 & 76 & 786 & 0.64 & $0.50-0.81$ & \\
\hline No & 1,617 & 175 & 1354 & 0.83 & $0.71-0.97$ & \\
\hline Inhaler check in prior year & & & & & & 0.89 \\
\hline Yes & 1397 & 34 & 276 & 0.80 & $0.56-1.13$ & \\
\hline No & 2126 & 328 & 2704 & 0.79 & $0.70-0.88$ & \\
\hline
\end{tabular}

COPD= chronic obstructive pulmonary disease. ICS=inhaled corticosteroid. LABA= long-acting beta agonist.

LAMA=long-acting muscarinic antagonist.

Table 4. The incidence rate ratios of GP consultations, respiratory events, and adverse-medication events, in the risk period after an inhaler switch compared to stable periods.

\begin{tabular}{|c|c|c|c|c|c|}
\hline Event & $\begin{array}{c}\text { Number of } \\
\text { patients }\end{array}$ & $\begin{array}{l}\text { Number of events in } \\
\text { 3-month risk period }\end{array}$ & $\begin{array}{c}\text { Number of events in } \\
\text { control period }\end{array}$ & IRR & $95 \% \mathrm{Cl}$ \\
\hline GP consultation & 50,289 & 143,602 & 926,991 & 1.00 & 0.99-1.01 \\
\hline Non-specific respiratory & 51,659 & 27,772 & 187,618 & 0.96 & $0.94-0.97$ \\
\hline Adverse-medication & 3,258 & 573 & 3,520 & 1.06 & $0.97-1.15$ \\
\hline
\end{tabular}

Switches could be between brand-to-generic, brand-to-brand, generic-to-generic or generic-to-brand. 